\title{
Effect of oral glucocorticoid treatment on serum inflammatory markers in acute asthma
}

\author{
A Sahid El-Radhi, Claire L Hogg, Jatinder K Bungre, Andrew Bush, \\ Christopher J Corrigan
}

\begin{abstract}
Background-Acute asthma is associated with elevated serum concentrations of products of activated $T$ cells and eosinophils.

Aims-To compare the changes in concentrations of these products with disease severity and changes in lung function following oral prednisolone treatment.

Methods-Twenty patients (mean age 8.7 years) were recruited on admission with acute asthma to a district general hospital. Disease severity was recorded before and after treatment with oral prednisolone using a validated pulmonary index score. Serum concentrations of interleukin (IL)-4, IL-5, soluble (s)CD25 (soluble IL-2 receptor), using a specific enzyme linked immunosorbent assay, and eosinophil cationic protein (ECP), using radioimmunoassay, were measured concomitantly. Non-asthmatic children ( $n=6$, mean age 9.2 years) undergoing elective surgery were recruited as controls, and serum samples were obtained on one occasion without treatment. Main outcome measures were changes in serum concentrations of cytokines and ECP, clinical asthma severity score, and peak expiratory flow rate.
\end{abstract}

Results-As expected, oral glucocorticoid treatment in the children with asthma was associated with clinical improvement and also with significant reductions in serum concentrations of IL-5 (mean 5.59 to 2.19 $\mathrm{pg} / \mathrm{ml}, \mathrm{p}=0.0001$ ), sCD25 (mean 2236 to $1772 \mathrm{pg} / \mathrm{ml}, \mathrm{p}=0.002$ ), and ECP (mean 54.3 to $33.1 \mathrm{pg} / \mathrm{ml}, \mathrm{p}=0.0001$ ). Serum IL-4 concentrations, in most patients and all the controls, remained below the sensitivity of the assay. However, serum concentrations of IL-5, sCD25, and ECP remained significantly higher than in controls, even after treatment with oral glucocorticoids $(p=0.03)$.

Conclusions-These data suggest that $T$ cell mediated inflammation may persist in childhood asthma despite apparent clinical remission associated with conventional doses of prednisolone. The long term consequences of persistent inflammation after an apparently treated acute attack of asthma require clarification. Clinical assessment and pulmonary function are inadequate surrogates for airway inflammation.

(Arch Dis Child 2000;83:158-162)
Keywords: asthma; cytokines; eosinophil cationic protein; prednisolone; lung; airway inflammation

In the past decade, bronchial biopsy and bronchoalveolar lavage in adult asthma have led to the concept that bronchial mucosal inflammation plays a fundamental role in the pathogenesis of asthma. This inflammation is characterised by $\mathrm{T}$ cell activation and airway eosinophilia. ${ }^{1}$ Local release of eosinophil granule proteins, of which eosinophil cation protein (ECP) is prototypical, is thought to cause bronchial mucosal damage and, ultimately, reversible airway obstruction and bronchial hyper-responsiveness. ${ }^{2}$ The influx of eosinophils is thought to be mediated by local release of eosinophil active cytokines by activated T cells, of which interleukin (IL) -5 is the most important. ${ }^{3}{ }^{4}$ IL-5 acts specifically on eosinophils, bringing about their recruitment and activation, and promoting their enhanced survival. IL-4, another product of activated T cells, may also play a role in eosinophil recruitment, as well as being one of only two cytokines known to initiate IgE synthesis in B cells, suggesting a further fundamental role for this cytokine in the pathogenesis of asthma. ${ }^{5}$ Glucocorticoids powerfully inhibit $\mathrm{T}$ cell activation and cytokine secretion, and this is probably one of the principal mechanisms by which they ameliorate asthma. ${ }^{6}$

We have previously shown elevated percentages of $\mathrm{T}$ cells expressing activation markers and mRNA encoding IL-4 and IL- 5 in the peripheral blood of both adults and children with asthma as compared with controls. ${ }^{7-10}$ Other groups have shown elevated concentrations of the soluble form of CD25 (sCD25), released by activated $\mathrm{T}$ cells, ${ }^{11}{ }^{12}$ and $\mathrm{ECP}^{13}$ in the serum of asthmatic adults and children compared with controls. Some of these studies have suggested a correlation between the concentrations of these products and disease severity, highlighting the possible role of these markers as simple objective measures to monitor disease activity and response to treatment.

In this study we wished to extend our previous observations on the properties of $\mathrm{T}$ cells and eosinophils in the peripheral blood of children with asthma, by measuring serum concentrations of their products during acute exacerbations, and changes in serum concentrations following oral gluccorticoid treatment. We hypothesised that serum concentrations of sCD25, IL-5, IL-4, and ECP would be elevated, compared with controls, during acute exacerbations in children with asthma, and that these concentrations would normalise con- 
Table 1 Derivation of pulmonary index score for asthma severity

\begin{tabular}{lllllll}
\hline Score & $\begin{array}{l}\text { Pulse rate } \\
\text { (beats/min) }\end{array}$ & Resp rate & Wheeze & $\begin{array}{l}\text { Access } \\
\text { muscles }\end{array}$ & SaO $_{2}(\%)$ & $\begin{array}{l}\text { PEFR }(\% \\
\text { Pred })\end{array}$ \\
\hline 1 & $<120$ & $<40$ & $\begin{array}{l}\text { None or end } \\
\text { expiratory }\end{array}$ & + +None & $96-100$ & $>70$ \\
2 & $120-140$ & $40-50$ & $\begin{array}{l}\text { Throughout } \\
\text { expiration }\end{array}$ & ++ & $92-95$ & $70-50$ \\
3 & $>140$ & $>50$ & $\begin{array}{l}\text { Inspiration and } \\
\text { expiration }\end{array}$ & +++ & $<92$ & $<50$
\end{tabular}

Score of 1-3 assigned for each clinical measurement or observation. Maximum score $=18$. Minimum score (no signs or symptoms) $=6$.

Resp, respiration; Access, accessory; PEFR, peak expiratory flow rate; Pred, prednisolone.

comitantly with systemic glucocorticoid treatment and clinical improvement. We measured the concentrations of these proteins in the serum of a group of children with moderate to severe asthma, before and after five days of oral prednisolone treatment, while monitoring lung function and clinical severity score. We also measured serum concentrations in controls matched, as far as possible, for age and atopic status.

\section{Methods}

SUBJECTS

Twenty children (14 boys, six girls; mean age 8.7 years, range $5-14$ years) known to have asthma and admitted to a district general hospital with an acute exacerbation formed the study group. We were not able to perform viral or other studies to determine the cause of the acute exacerbation. Sixteen of these children were atopic (see definition below). Exclusion criteria included a history of chronic lung disease such as bronchopulmonary dysplasia, cystic fibrosis, or other definite systemic disease, presence of stridor, suspicion of foreign body inhalation, or use of systemic steroids within the previous 24 hours. After clinical examination the children were assigned a pulmonary index disease severity score based

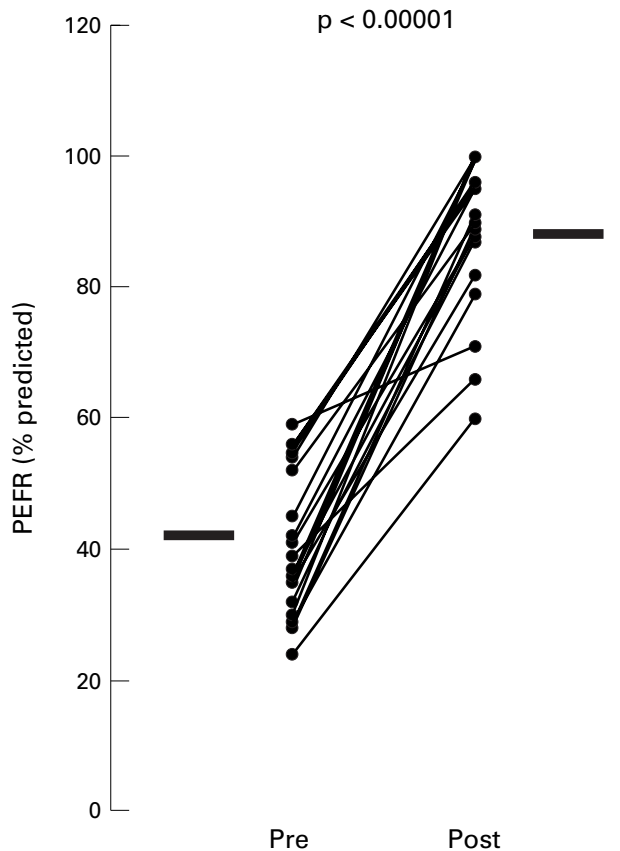

on pulse rate, respiratory rate, usage of accessory muscles of respiration, presence or absence of audible wheeze, oxygen saturation in room air, and peak expiratory flow rate. For each of these six measurements or observations, a score of 1-3 was assigned (table 1 ), resulting in a possible minimum score of 6 (normal) and maximum score of 18 . Scores were assigned on admission, and seven days later, by a single observer (A S E-R) before any laboratory measurements were made. All children were treated with oral prednisolone 2 $\mathrm{mg} / \mathrm{kg} /$ day (maximum $40 \mathrm{mg} /$ day) for five days and with oxygen and inhaled $\beta_{2}$-agonist as required. None required intravenous treatment or antibiotics.

CONTROLS

Six healthy children (two boys, four girls; mean age 11 years, range $7-16$ years), who required a blood test in the course of minor elective surgical procedures, were recruited as controls. Two of these children were atopic. No child had any previous symptoms of asthma.

ETHICS

This study was approved by the research ethics committee at Queen Mary's Hospital, Sidcup. Informed written consent was obtained from parents or guardians for their children to participate in the study.

\section{DEFINITION OF ATOPY}

For the purposes of this study, atopy was defined as a positive skin prick test (wheal diameter $>4 \mathrm{~mm}$ at 15 minutes) to extracts of three common aeroallergens (mixed grass pollen, cat dander, house dust mite: Soluprick; ALK, Horsholm, Denmark) and/or a serum IgE concentration > $150 \mathrm{IU} / \mathrm{ml}$ (PRIST; Pharmacia, Uppsala, Sweden).

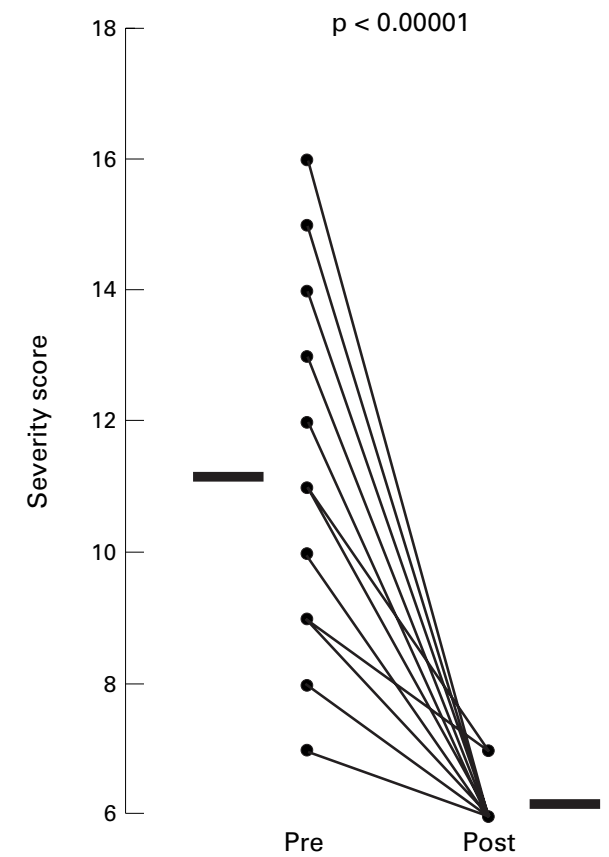

Figure 1 Changes in peak expiratory flow rate (PEFR, \% predicted) and asthma severity scores in the 20 children with acute severe asthma before (Pre) and after (Post) oral prednisolone treatment. Bars represent mean values. Statistical comparisons by paired t test. 
Table 2 Serum analyte concentrations in children with asthma before and after oral prednisolone treatment, and the normal controls

\begin{tabular}{llllll}
\hline \multirow{2}{*}{ Analyte } & \multicolumn{2}{l}{ Serum concentration } & & \\
\cline { 2 - 3 } & Before & After & Controls & p Value & p Valuet \\
\hline IL-5 & $5.59(0.71)$ & $2.19(0.18)$ & ND & 0.0001 & 0.03 \\
IL-4 & $0.56(0.25)$ & $2.20(1.13)$ & ND & NS & NS \\
SCD25 & $2236(192)$ & $1172(175)$ & $506(34)$ & 0.002 & 0.03 \\
ECP & $54.3(4.7)$ & $33.1(3.7)$ & $15.5(1.9)$ & 0.0001 & 0.03 \\
\hline
\end{tabular}

Values are mean (SEM) expressed as $\mathrm{pg} / \mathrm{ml}$. Measurements below the detection limit of the assays (ND) were regarded as zero.

* Student's paired $t$ test comparing children with asthma before and after treatment.

+Wilcoxon signed ranks test comparing chidren with asthma after treatment and controls. IL, interleukin; sCD25, soluble CD25; ECP, eosinophil cationic protein.
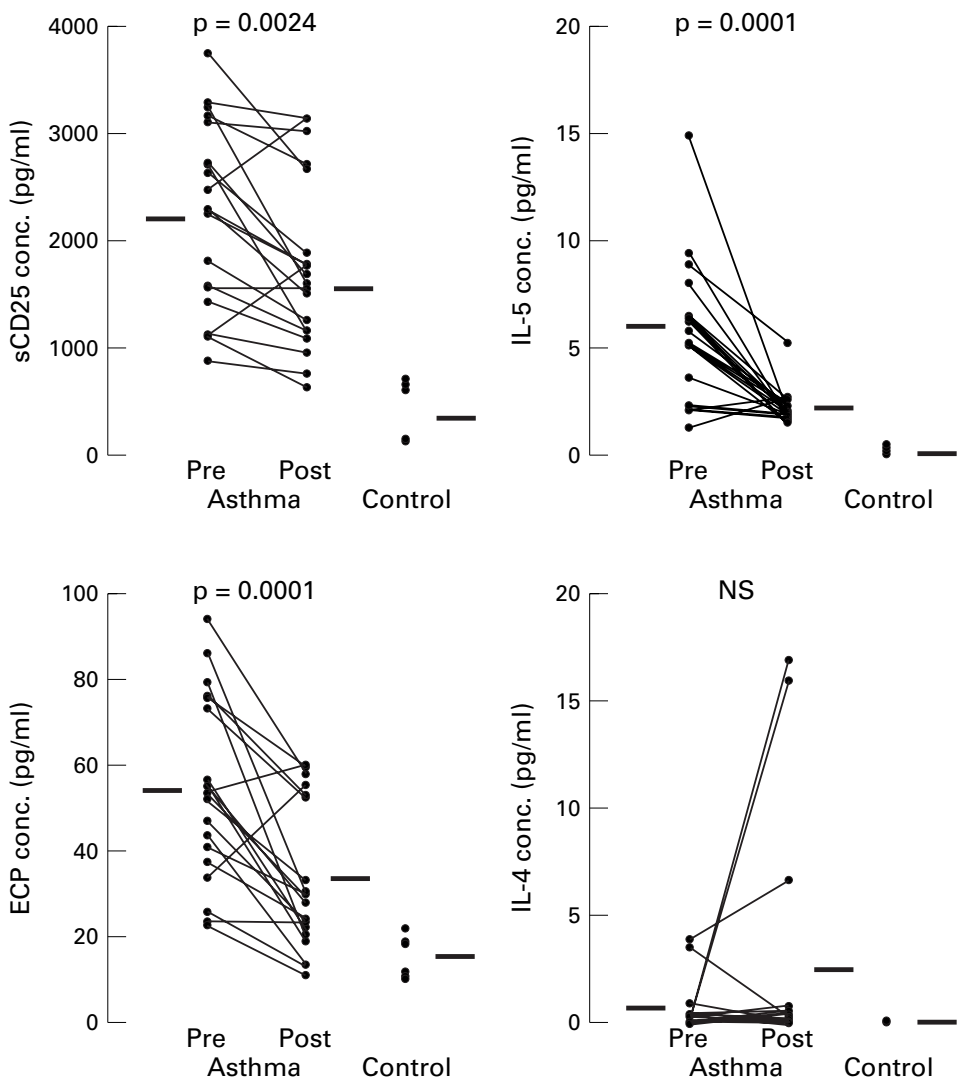

Figure 2 Serum concentrations of interleukin (IL)-5, IL-4, soluble CD25 (sCD25), and eosinophil cationic protein (ECP) in 20 children with acute severe asthma before (Pre) and after (Post) a course of oral prednisolone (2 $\mathrm{mg} / \mathrm{kg} /$ day; five days) and six non-asthmatic controls. Bars represent mean values. Statistical comparisons by paired t test.

BLOOD SAMPLING AND MEASUREMENT OF SERUM ANALYTES

Peripheral venous blood (3-5 ml) was drawn from the children with asthma at admission before glucocorticoid treatment, and again after five days of treatment at about the same time of day. A single sample was drawn from the control subjects. Blood was allowed to clot on plain glass for one hour at $20^{\circ} \mathrm{C}$, after which serum was recovered by centrifugation and stored at $-80^{\circ} \mathrm{C}$ pending analysis. Serum concentrations of IL-5, IL-4, and sCD25 (soluble IL-2 receptor) were measured by commercial sandwich enzyme linked immunosorbent assay (ELISA) calibrated with recombinant human standards (R\&D Systems, Abbingdon, Oxon, UK). The assays were sensitive above $1.8 \mathrm{pg} / \mathrm{ml}$ (IL-5), $0.012 \mathrm{pg} / \mathrm{ml}$ (IL-4, high sensitivity assay), and $56 \mathrm{pg} / \mathrm{ml}$ (sCD25). Serum ECP concentrations were measured with a commer- cial radioimmunoassay kit (Pharmacia) sensitive above $2 \mathrm{pg} / \mathrm{ml}$. Samples were diluted, where necessary, so that all measurements fell within the ranges of the standard curves. For each analyte, duplicate measurements were made contemporaneously in the same assay.

STATISTICAL METHODS

Statistical comparisons were made between serum concentrations of cytokines before and after prednisolone treatment using Student's paired $t$ test. This test was also used to compare changes in peak expiratory flow rates and asthma severity scores. The non-parametric Wilcoxon signed ranks test was used to compare serum ECP, sCD25, and IL-5 concentrations between patients and controls. The $\mathrm{p}$ values shown in fig 3 are derived from Pearson's linear regression analysis.

\section{Results}

CLINICAL RESPONSE OF PATIENTS WITH ASTHMA TO TREATMENT

In the children with asthma, the mean (SEM) severity score was 11.2 (2.3) on admission. After one week, most patients were essentially asymptomatic (mean score $6.1(0.4)$ ). The mean (SEM) peak expiratory flow rate in the children with asthma was 41 (6)\% of the predicted value on admission and 88 (3)\% after one week. Both of these changes were significant (fig 1).

\section{SERUM ANALYTE CONCENTRATIONS}

IL-5

IL-5 was detectable in the serum of all 20 children with asthma on admission, but undetectable using the same assay in all six controls. Prednisolone treatment was associated with a significant reduction in serum IL-5 concentration (5.59 (0.71) to $2.19(0.18) \mathrm{pg} / \mathrm{ml}$, $\mathrm{p}=0.0001$; fig 2 , table 2 ), which nevertheless remained significantly elevated at the end of the study compared with that of the controls (2.19 (0.18) $\mathrm{pg} / \mathrm{ml} v$ undetectable, $\mathrm{p}=0.03$; table 2).

\section{$I L-4$}

Even with the use of a high sensitivity ELISA, IL-4 was detectable in the serum of only a minority of the patients with asthma on admission, and was undetectable in all of the controls. In three patients, prednisolone treatment was associated with a measurable increase in serum IL- 4 concentrations, but in the majority IL-4 remained low, and the changes in the group as a whole were not statistically significant (fig 2, table 2).

$s C D 25$ (sIL-2 receptor)

sCD25 was detectable in the serum of all 20 children with asthma on admission and also in all six controls (fig 2, table 2). Prednisolone treatment was associated with a significant reduction in serum sCD25 concentrations (2236 (192) to 1772 (175) pg/ml, $\mathrm{p}=0.002$ ), which nevertheless remained elevated compared with the controls even after treatment (1172 (175) pg/ml v 506 (34) pg/ml, p = 0.03; table 2). 


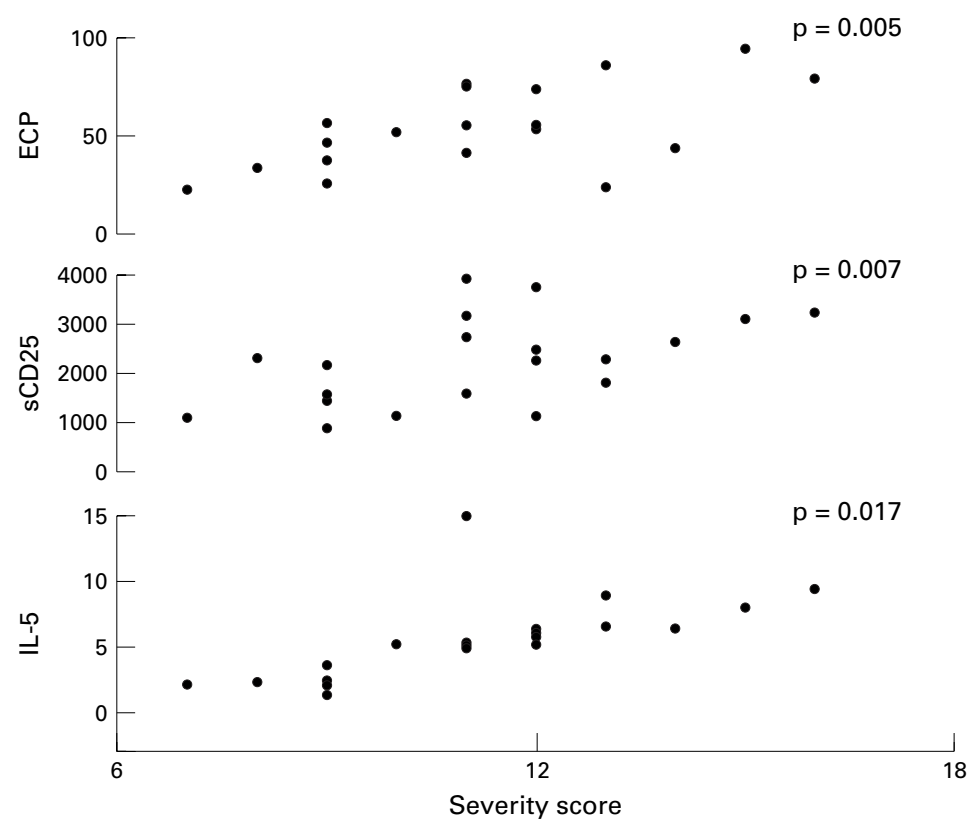

Figure 3 Relation between serum concentrations of interleukin-5 (IL-5), soluble CD25 (sCD25), and eosinophil cationic protein (ECP) and severity scores in the children with asthma on admission. All measurements are in $\mathrm{pg} / \mathrm{ml}$. p values by Pearson's linear regression.
It may be thought surprising that we were unable to detect IL-4 in the serum of most of our asthmatic patients despite using a high sensitivity assay. Increases in serum IL-4 concentrations were seen in three of these patients following glucocorticoid treatment, but the changes in the group as a whole were not significant. In a large study ${ }^{14}$ comparing atopic and non-atopic children of different ages, IL-4 was only increased in the serum of the atopic children, as compared with the controls, when a high sensitivity ELISA was used, but there was no correlation with the presence and severity of asthma. Two further studies on adults $^{15}$ and children ${ }^{16}$ have shown essentially similar results. Overall, these data suggest that serum IL-4 concentrations may be slightly elevated in atopic patients compared with nonatopic controls, irrespective of whether or not they have asthma. Even so, direct correlations between serum IL- 4 and total IgE concentrations in these patients, where sought, ${ }^{14}{ }^{15}$ have not been found. It is possible that inappropriate IgE synthesis may not require continuous elevated IL- 4 synthesis, at least as reflected by serum concentrations.

The main point of interest in this study is that the serum concentrations of these asthma relevant analytes were still clearly elevated in the children with asthma compared with normal controls even after treatment resulting in resolution of all signs and symptoms as judged by clinical and spirometric criteria. The clinical significance of this finding is unclear. It may be that these serum inflammatory changes resolved spontaneously within a few days. This could be investigated by a further study taking serial blood samples, although this may not be considered ethical. These data suggest that more prolonged intensive anti-inflammatory treatment may be warranted in acute exacerbations of childhood asthma. Further clinical and immunological studies are required to investigate the long term consequences of apparently untreated inflammation. However, this study does highlight the deficiencies of relying on clinical assessment and pulmonary function to monitor an inflammatory airway disease such as asthma, and the response to treatment with anti-inflammatory medication.

Cysteinyl leukotrienes are mediators that are also believed to be important in the pathogenesis of asthma. Of interest and in accord with the findings of our study was a report that plasma leukotriene $\mathrm{B}_{4}$ and urinary leukotriene $\mathrm{E}_{4}$ were increased in acute asthma, ${ }^{17}$ and fell in association with oral corticosteroids, but remained significantly above normal one month later, again implying continuing inflammation despite an apparently adequate clinical response.

More importantly, this study has shown that, despite the usual course of prednisolone for acute asthma, there is evidence of continuing airway inflammation despite resolution of symptoms and normalisation of pulmonary function.

This study was funded partly by the National Asthma Campaign and the Medical Research Council (UK). served correlations between disease severity on admission and serum concentrations of these mediators further support this concept. 
1 Azzawi M, Bradley B, Jeffery PK. Identification of activated T lymphocytes and eosinophils in bronchial biopsies in
stable atopic asthma. Am Rev Respir Dis 1990;142:1407stable

2 Frigas E, Loegering DA, Solley G, Farrow G, Gleich GJ. Elevated levels of the eosinophil major basic protein in the sputum of patients with bronchial asthma. Mayo Clin Proc 1981;56:345-53.

3 Shi H, Qin S, Huang G, et al. Infiltration of eosinophils into the asthmatic airways caused by interleukin-5. Am f Respir Cell Mol Biol 1997;16:220-4.

4 Shi H, Xaio C, Zhong D, et al. Effect of inhaled interleukin- 5 on airway hyperreactivity and eosinophilia in asthmatics. Am F Respir Crit Care Med 1998;157:204-9.

5 Del Prete GF, Maggi E, Parronchi P, et al. IL-4 is an essential factor for the IgE synthesis induced in vitro by human $\mathrm{T}$ cell clones and their supernatants. F Immunol 1988;140: 4193-8.

6 Robinson DS, Hamid O, Sun Ying, et al. Prednisolone treatment in asthma is associated with modulation of bronchoalveolar lavage interleukin-4, interleukin-5 and interferon- $\gamma$ cytokine gene expression. Am Rev Respir Dis interferon- $\gamma$ cyto

7 Gemou-Engasaeth V, Kay AB, Bush A, Corrigan CJ Activated peripheral blood CD4 and CD8 T lymphocytes in child asthma: correlation with eosinophilia and disease severity. Pediatr Allergy Immunol 1994;5:170-7.

8 Gemou-Engasaeth V, Bush A, Kay AB, Hamid Q, Corrigan CJ. Inhaled glucocorticoid therapy of childhood asthma is associated with reduced peripheral blood $\mathrm{T}$ cell activation and "Th-2 type" cytokine mRNA expression. Pediatrics $1997 ; 99 ; 695-703$.

9 Corrigan CJ, Hackzu A, Gemou-Engasaeth V, et al. $\mathrm{CD}_{4} \mathrm{~T}$ lymphocyte activation in asthma is accompanied by serum concentrations of IL-5: effect of glucocorticoid therapy. $A m$ Rev Respir Dis 1993;147:540-7.

10 Corrigan CJ, Hamid Q, North J, et al. Peripheral blood $\mathrm{CD}_{4}$, but not $\mathrm{CD}_{8}$, $\mathrm{T}$ lymphocytes in patients with exacerbation of asthma transcribe and translate messenger RNA encoding cytokines which prolong eosinophil survival in the context of a Th2 type pattern: effect of glucocorticoid therapy. Am f Respir Cell Mol Biol 1995;12:567-78.

11 Motojima S, Hirata A, Kushima A, et al. Serum levels of soluble interleukin-2 receptor in asthma patients. $\mathcal{F}$ Asthma 1995;32:151-8.

12 Hoeger PH, Niggermann B, Ganschow R, Dammann C, Haeuser G. Serum levels of sCD23 and sCD25 in children with asthma and in healthy controls. Allergy 1994;49:21722 .

13 Motojima S, Tateisha K, Koseki T, Makino S, Fukuda T. Serum levels of eosinophil cationic protein and interleukin-5 in patients with asthma without systemic corticosteroids. Int Arch Allergy Immunol 1997;114(suppl 1):55-9.

14 Oshhima Y, Katamura k, Miura M, Mikawa H, Mayumi M. Serum levels of IL-4 and soluble CD23 in children with allergic disorders. Eur f Pediatr 1995;154:723-8.

15 Matsumoto K, Taki F, Miura M, Matsuzaki M, Takagi K. Serum levels of soluble IL-2R, IL-4 and soluble Fc Epsilon R11 in adult bronchial asthma. Chest 1994;105:681-6.

6 Hashimoto S, Amemiya E, Tomita Y, et al. Elevation of soluble IL-2 receptor and IL-4, and non-elevation of IFNgamma in sera from patients with allergic asthma. Ann Allergy 1993;71:455-8.

17 Sampson AP, Castling DP, Green CP, Price JF. Persistent increase in plasma and urinary leukotrienes after acute asthma. Arch Dis Child 1995;73:221-5. 